\title{
Saúde, trabalho e subjetividade: absenteísmo-doença de trabalhadores em uma universidade pública
}

\author{
Health, labor and subjectivity: considerations about absenteeism-disease of workers at a \\ public university
}

\author{
Solange Vianna Dall'Orto Marques ${ }^{1}$ \\ Gabriela de Brito Martins ${ }^{2}$ \\ Oswaldo Cruz Sobrinho ${ }^{3}$
}

\section{Resumo}

O trabalho é uma construção sócio-histórica e está em constante mudança. É um processo instável, uma invenção humana que se institui em cada posto de trabalho e em cada trabalhador. A ergonomia se propõe a contribuir na compreensão do trabalho em sua complexidade. O norteador no presente artigo será a saúde dentro de um contexto de trabalho. Desta forma, foram privilegiados os estudos oriundos da e na ergonomia, como Wisner e Falzon, e particularmente os estudos dos autores Schwartz e Clot, que partiram da ergonomia francesa para ampliar as propostas de análise da atividade de trabalho, o primeiro com a Ergologia e o segundo com a Clínica da Atividade. Como caminho metodológico, optou-se por utilizar uma pesquisa documental, descritiva e quantitativa, por dados primários, que mapeou as licenças médicas apresentadas pelos servidores da Universidade pesquisada no período de março/2007 a fevereiro/2009, como justificativa de ausência ao trabalho. Com o entendimento de que o trabalho se configura como fator preponderante no processo de saúde e adoecimento destes trabalhadores e as possibilidades de ação sobre os impactos dos novos modos de viver e trabalhar na saúde dos trabalhadores. Os ganhos desta reflexão são plurais, não apenas no sentido de todos os envolvidos no processo, mas nas possibilidades que se abrem para avançar no tema. Os dados desta pesquisa indicam que não é possível pensar o adoecimento dos trabalhadores e as faltas ao trabalho de forma descolada da vida. Os transtornos mentais e comportamentais e as doenças do sistema osteomuscular e do tecido conjuntivo, que predominam na população pesquisada, são apenas emergência de outros processos que os subsidiam, resultam, assim, não de fatores isolados, mas de contextos de trabalho em interação com o corpo e o aparato psíquico dos trabalhadores. Tendo como certo a inevitável interação do homem com o trabalho, essas considerações possibilitam também uma reflexão sobre o trabalho dos profissionais de saúde na instituição pesquisada, propiciando uma discussão que não somente evite a degradação da saúde, mas que, numa abordagem ativa da saúde do trabalhador, amplie as possibilidades de construção e reinvenção da relação saúde e trabalho.

Palavras-chave: Absenteísmo. Universidade. Saúde. Trabalho. Subjetividade.

Artigo submetido em 10 de dezembro de 2010 e aceito para publicação em 27 de abril de 2011.

${ }^{1}$ Mestranda em Administração pela Universidade Federal do Espírito Santo; Psicóloga da Universidade Federal do Espírito Santo. Endereço: Secretaria de Assuntos Comunitários/UFES, Avenida Fernando Ferrari, 514 - Campus Universitário, Goiabeiras, CEP 29075-910, Vitória, ES, Brasil. E-mail: solange.ufes@hotmail.com

${ }^{2} \mathrm{M}$

Mestranda em Administração pela Universidade Federal do Espírito Santo; Psicóloga da Apsi Consultoria e Professora do Colegiado de Psicologia do Centro Universitário São Camilo-ES. Endereço: Praça Gillberto Machado, 15 - 1ำ andar, Gilberto Machado, CEP 29303-290, Cachoeiro de Itapemirim, ES, Brasil. E-mail: martins.gabby@gmail.com

${ }^{3}$ Especialista em Perícia Médica; Médico do Trabalho da Universidade Federal do Espírito Santo. Endereço: Secretaria de Assuntos Comunitários/UFES, Avenida Fernando Ferrari, 514 - Campus Universitário, Goiabeiras, CEP 29075-910, Vitória, ES, Brasil. E-mail: ocsobrinho@unimed.com.br 


\begin{abstract}
Labor is a socio-historical construction and it is constantly changing. It is an unstable process, a human invention that is established in every workplace and every worker. Ergonomics aims to contribute to the understanding of work in its complexity. The guideline in this article will be health within a working context. Thus, the focus is on studies of ergonomics, such as those of Wisner and Falzon, and particularly works by the authors Schwartz and Clot, that were based on French Ergonomics to expand the proposal analysis of labor activity, the first with Ergology and the second with Activity Clinics. As the methodological option, we chose to conduct documentary, descriptive and quantitative research by primary data, which mapped the sick leave claimed by the civil servants at the University under study from March, 2007 to February, 2009 to justify why they were absent from work. With the understanding that labor takes shape as a major factor in the process of health and illness in workers and the possibility of the impact of new ways of living and working on the health of workers. The gains of this reflection are plural, not only in the sense of everyone involved in the process, but in the possibilities that open up further developments in the theme. Data from this study indicate that it is not possible to think about the workers' illness, absences from work in a way that detaches them from life. The mental and behavioral disorders and diseases of the musculoskeletal system and connective tissues that predominate in the population under study only emerge from other processes that support them, resulting, therefore, not in isolated factors, but in labor contexts in interaction with the body and the psychic apparatus of the workers. Granted the inevitable interaction of man and labor, these considerations also allow a reflection on the work of health professionals in the institution under study, opening up a discussion that not only prevents the degradation of health, but which, in an active approach to the workers' health, extends the possibilities of construction and reinvention of health and labor.
\end{abstract}

Keywords: Absenteeism. University. Health. Labor. Subjectivity.

\title{
Introdução
}

O Trabalho é construção sócio-histórica, um processo instável e em constante mudança, uma invenção humana que se institui em cada posto de trabalho e em cada trabalhador. Maggi e Tersac (2004) trazem o sentido do trabalho como dinâmico, que varia de uma sociedade para outra e ao longo do tempo, só podendo ser compreendido no contexto em que está sendo analisado.

Nesse cenário, não há como uma disciplina ou saber darem conta da complexidade que envolve o trabalho e suas relações. Assim, o presente estudo se propõe a um recorte limitado, parcial, e dentro de um contexto histórico específico, partindo dos estudos da ergonomia francesa.

A ergonomia contribui na compreensão do trabalho em sua complexidade. Segundo Daniellou (2004, p.17) "A Ergonomia leva em conta, classicamente, um duplo critério: o de saúde dos trabalhadores e o de eficácia econômica". O norteador nesse artigo será a saúde dentro de um contexto de trabalho. Dessa forma privilegiaram-se os estudos oriundos da e na ergonomia, como Wisner e Falzon, e particularmente os estudos dos autores Schwartz e Clot, que partiram da ergonomia francesa para ampliar as propostas de análise da atividade de trabalho, o primeiro com a Ergologia e o segundo com a Clínica da Atividade.

Schwartz (2000) acrescenta à análise da atividade do trabalho o conceito do uso de si, reforçando que a atividade não se restringe ao prescrito, é mais ampla, é da ordem do real, impossível de ser retido e até mesmo de ser verbalizado. O trabalho é o lugar de um problema, de uma tensão problemática, de um espaço de possíveis a negociar. Para esse autor (2000, p.34) "o trabalho não é mera execução, mas uso, já que o indivíduo é constantemente convocado a manifestar-se de forma que escapam aos enquadramentos e regras pré-estabelecidas".

Ainda nessa linha, Clot (2007a) afirma que o trabalho possui uma abordagem central e insubstituível na construção da identidade e da saúde dos trabalhadores. A Clínica da Atividade proposta por Clot (2007b, 
p.59) aborda o trabalho como "o lugar em que se desenrola para o sujeito a experiência dolorosa e decisiva do real, que resiste à sua capacidade, competências, a seu controle".

O trabalho está carregado de sentidos. Em nossa cultura ele é também um organizador social e investe os atores sociais de identidade, pois, por meio dele, o sujeito se reconhece e é reconhecido na sua atividade profissional. Essa importância torna o trabalho um espaço privilegiado para compreender os processos de construção de subjetividades do indivíduo e da sociedade, e suscita um olhar para ir além do que está aparente, buscando a construção singular e coletiva nos postos de trabalho, nas interações, no dito e no não dito, no próprio trabalho e na falta dele.

O trabalho para Maggi e Tersac (2004) é uma necessidade e um desejo, e este mesmo trabalho que permite a sobrevivência também se constitui como um responsável que contribui significativamente para o adoecimento dos trabalhadores.

O Ministério da Saúde (BRASIL, 2001, p.161) destaca que em decorrência do importante lugar que o trabalho ocupa na vida das pessoas, "sendo fonte de subsistência e de posição social, a falta de trabalho ou mesmo a ameaça de perda do emprego geram sofrimento psíquico, pois ameaçam a subsistência e a vida material do trabalhador e de sua família". Nesse documento, a posição do Ministério da Saúde vai além ao dizer que o trabalho "ao mesmo tempo abala o valor subjetivo que a pessoa se atribui, gerando sentimentos de menos-valia, angústia, insegurança, desânimo e desespero, caracterizando quadros ansiosos e depressivos".

Com o entendimento de que o trabalho se configura como fator preponderante no processo de saúde e adoecimento dos trabalhadores, este estudo se propõe, a partir de considerações sobre o mapeamento das licenças médicas apresentadas pelos trabalhadores de uma instituição de ensino, a suscitar uma discussão sobre a saúde desses trabalhadores e as possibilidades de ação sobre os impactos dos novos modos de viver e trabalhar.

\section{O Método}

Como caminho metodológico optou-se por utilizar a pesquisa documental, descritiva e quantitativa, por dados primários, que mapeou as licenças médicas apresentadas pelos trabalhadores da Universidade pesquisada, no período de março/2007 a fevereiro/2009, como justificativa de ausência ao trabalho.

A pesquisa foi realizada na Universidade Federal do Espírito Santo-UFES, única universidade pública do estado do Espírito Santo, e a população estudada foi composta do universo dos trabalhadores dessa instituição, distribuídos pelos seus quatro campi, dois deles localizados na capital Vitória e os outros dois no interior do estado. Fez parte da pesquisa, enquanto sujeitos, o conjunto de trabalhadores ativos afastados por licença para tratar da própria saúde, dentro do intervalo de 24 (vinte e quatro) meses, período histórico utilizado como referência para a coleta e análise dos dados.

Todos os atestados apresentados à Junta Médica Pericial da Universidade, no período estudado, foram utilizados na pesquisa, sem perda de dados. Tendo sido identificadas todas as licenças registradas, possibilitando que um mesmo trabalhador tenha produzido vários eventos, havendo, portanto, repetições.

Por ser uma pesquisa documental, dois vieses são possíveis e não são controlados por essa pesquisa: os dias não trabalhados por motivo de tratamento da saúde, em que os servidores podem ter faltado ao trabalho, mas 
não apresentaram atestados médicos para justificar essa ausência, bem como a apresentação de atestados com licenças negadas pela Junta Médica Pericial, que não são registrados.

O acesso aos dados ocorreu após autorização institucional e foi facilitado pelo fato de dois dos pesquisadores serem integrantes da equipe multidisciplinar de saúde da Universidade, e trabalharem no setor responsável pelos registros. A pesquisa não levantou qualquer dado pessoal ou profissional dos servidores que apresentaram os atestados no período pesquisado.

$\mathrm{Na}$ análise dos documentos buscou-se apenas a causa e a duração em dias dos afastamentos, com base na classificação internacional de doenças - CID-10. Posteriormente esses dados foram agrupados, gerando um mapeamento dos afastamentos por doenças na UFES, informando o número de atestados homologados, os dias de trabalho perdidos, e as causas do afastamento.

Não foram categorizadas informações quanto à faixa etária, ao sexo, ao setor, ao cargo, ao tempo de trabalho, entre outros, pontos importantes para uma futura abordagem, com outros objetivos e recortes. Foi considerado apenas o número de dias de afastamento e de eventos, verificando a prevalência das doenças no período pesquisado, sem identificar a incidência desses eventos.

\section{O Absenteísmo}

Para Penatti, Zago e Quelhes (2006) absenteísmo é a ausência do trabalhador do seu local de trabalho, também denominado de ausentismo, e se traduz pelos atrasos, ausências e faltas dos trabalhadores em horário determinado para sua jornada de trabalho. O absenteísmo é multifatorial e um desafio para as organizações, visto que é considerado como um grande prejuízo econômico tanto para o trabalhador como para a organização.

Dejours (1992) trata o absenteísmo como um escape do trabalhador, uma busca por equilíbrio diante da insatisfação no trabalho, uma alternativa quando se chega ao limite. Nesse prisma, pode-se pensar o absenteísmo como uma forma de resistência frente às demandas de um trabalho "adoecedor". É uma forma encontrada pelo trabalhador para resistir, escapar, fazendo um enfrentamento possível à situação que se encontra.

Para Wisner (1994) o absenteísmo se apresenta como um sinal de desequilíbrio, e os altos índices de absenteísmo estão relacionados, para esse autor, às síndromes psicológicas vinculadas ao desgaste do trabalhador nos processos de trabalho, à precarização do trabalho e correlatos.

Essa pesquisa se concentrou no absenteísmo-doença, ou seja, nas ausências ao trabalho que se justificaram pela apresentação de um atestado médico. No entanto foram descartadas por sua natureza as licenças por parto e para acompanhamento de pessoa da família, que não se configuram como causas de tratamento da saúde do próprio trabalhador, apesar de originadas a partir de um atestado médico.

O conceito de absenteísmo que subsidiou as considerações de afastamento por saúde desse trabalho foi o da Organização Internacional do Trabalho, trazida por Silva, Pinheiro e Sakurai (2008, p.1), sendo o "período de ausência laboral que se aceita como atribuível a uma incapacidade do indivíduo, exceção para aquela derivada de gravidez normal ou prisão. Entende-se por ausência laboral o período ininterrupto de falta ao trabalho, desde seu começo, independentemente da duração". 


\section{A Saúde e a Saúde do Trabalhador}

Dejours (1986, p.8) faz críticas ao conceito de saúde proposto pela Organização Mundial de Saúde, que entende saúde como "o completo bem-estar físico, mental e social e não a simples ausência da doença". O autor afirma que essa perfeição, esse completo bem-estar não existe, e revela: "tenderíamos a dizer que a saúde é antes de tudo um fim, um objetivo a ser atingido. Não se trata de um estado de bem-estar, mas de um estado do qual procuramos nos aproximar".

Para Canguilhem (1990) a saúde não pode ser um conceito científico, mas uma construção, capacidade do ser humano de ir muito além de se adaptar ao meio em que vive, buscar novas interações nas situações que se colocam, instituir novas normas, o que ocorre sempre, pois é inerente ao humano, que, ao se ver diante de novas demandas, cria, reconstrói, rearranja suas antigas normas.

Assim como o trabalho é uma construção social, o conceito de saúde também o é. Constitui uma leitura da sociedade que determina o que é doença e saúde, muitas vezes independente do sujeito envolvido. Canguilhem (1990) já trazia essa questão da normatividade, tanto do indivíduo como da sociedade, pois o homem é demandado a posicionar-se, a fazer escolhas, e isso se dá na relação com o seu próprio meio, onde o homem constrói e é construído e dá sentido a sua vida e ao seu trabalho, e consequentemente à sociedade.

A preocupação com a saúde do trabalhador ganha corpo com o início da Medicina do Trabalho, abordagem que se restringe a uma visão biológica e individual do trabalhador. Este conceito foi sendo substituído pelo de Saúde Ocupacional, em que o ambiente no qual o trabalhador está inserido passa a ser considerado na relação saúde/doença, iniciando um movimento de prevenção. Na atualidade, a referência é a Saúde do Trabalhador que traz uma mudança conceitual, relacionando a saúde com o processo de trabalho, considerando a subjetividade do trabalhador. As organizações convivem hoje com formas híbridas dos três modelos citados.

Mendes e Dias (1991) relatam que a abordagem da Saúde do Trabalhador tende a romper com uma concepção hegemônica de dicotomia saúde-doença e com a simplória relação causal entre doença e agente causador ou grupo de riscos, que foca o processo produtivo e desconsidera a subjetividade. Os autores vão além, ao considerar que o trabalho não é apenas espaço de submissão e dominação pelo capital, mas também lugar de resistência e de fazer histórico.

Saúde do trabalhador é para Gomes-Minayo e Thedim-Costa (1997, p.21) "um corpo de práticas teóricas interdisciplinares - técnicas, sociais, humanas - e interinstitucionais, desenvolvidas por diversos atores situados em lugares sociais distintos e informados por uma perspectiva comum". Para Brito (2004, p.100) "é acima de tudo uma perspectiva de estudo, atenção e intervenção sobre os problemas relativos à saúde dos trabalhadores; uma forma de ver, entender e desenvolver ações práticas, a partir de olhares de diferentes especialistas e olhares dos trabalhadores".

Nessa perspectiva a saúde é, assim como o trabalho, um processo em construção. Para Falzon (2004) os estudos organizacionais relacionados à saúde do trabalhador devem ocupar-se não somente de ações que evitem a degradação da saúde, mas também da pesquisa de condições que favoreçam a sua construção.

O desafio para os profissionais, que se propõem a estudar e adotar políticas dentro da perspectiva dos diversos olhares que podem contribuir nesse processo, é pensar o sujeito como atuante na construção de sua saúde e nas relações estabelecidas com o trabalho. É sabido que muitas atividades laborais trazem danos à saúde e que existe sempre a necessidade de adotar, conforme aponta Sato (2002), outros modos de combinar os sistemas técnico e social, em um replanejamento que, de acordo com a concepção, vai pensar, de uma maneira ou outra, novas formas de trabalho. 
Apesar de não ser uma questão limitadora, os nexos causais entre os processos de produção e a saúde já são largamente comprovados, assim como a redução de danos quando se implementam programas de prevenção. Os projetos educacionais ou a adoção de estratégias que focam a prevenção nos ambientes laborais, através de várias metodologias como programas de educação continuada, palestras, informativos, exames periódicos, redução de riscos, correções ergonômicas, e outros, são significativos para melhoria da saúde do trabalhador e da produtividade da empresa.

Couto (2005) afirma que os estudos baseados na ergonomia podem melhorar enormemente a qualidade de vida dos trabalhadores. Como uma disciplina que abarca diferentes saberes, o autor destaca que, quando se encaram os desafios presentes nas formas de realizar o trabalho, buscando corrigir situações causadoras de dor, fadiga, desconforto, entre outros, se ganha em qualidade de vida para os trabalhadores.

Sato (2001) escreve que, quando existe um investimento por parte das organizações nos processos preventivos em saúde, através de diferentes intervenções em que o trabalhador possa interagir sobre as condições do ambiente de trabalho, ainda que seja um processo controverso, não se podem desconsiderar os ganhos desses projetos. Nesse cenário tem-se um trabalhador mais consciente, exigente e responsável na construção da saúde, por mais passivo e desigual que esse possa parecer na relação capital-trabalho, o que vai depender do contexto sóciopolítico.

Sato (2001, p.75) alerta que "[...] se o trabalhador não tem controle sobre o contexto de seu trabalho, pode-se estabelecer uma "ruptura", traduzida em manifestações de sofrimento e de doenças (mentais, psicossomáticas e físicas, como as LER-Lesões por Esforços Repetitivos)".

Assim, o trabalhador que não percebe contextualmente o seu trabalho e suas implicações no mesmo, não consegue construir estratégias de enfrentamento, podendo favorecer um processo de adoecimento, sofrimento e distanciamento. Desse modo, ao discutir saúde do trabalhador, não se pode desconsiderar o indivíduo como sujeito de suas ações, ativo na produção de sua própria saúde, tanto nas relações que estabelece com o meio, com o posto de trabalho, como com as reflexões e escolhas que faz para si mesmo. Isso não significa atribuir ao indivíduo a responsabilidade do processo, mas marcar o lugar do trabalhador como importante elo para as produções subjetivas e engendradas na nossa sociedade.

O trabalho traz sofrimento exatamente porque é lugar de prazer e de satisfação e, quando não existe satisfação, favorece-se o adoecimento. Para Dejours (1992), o trabalho nunca será indiferente à saúde - ou ele contribui para a promoção da saúde ou para sua deterioração. A doença no trabalho tem relação direta com os modos de trabalhar, com a atividade de trabalho, mas não é só isso. Como já dito, não é uma simples relação de causa e efeito, mas uma complexa rede de relações, encontros, tensões e espaço de luta constante.

$\mathrm{Na}$ Universidade pesquisada existem ações com foco na saúde do trabalhador, mas essas estão divididas nas especialidades de cada profissional, que age de forma autônoma e sem a participação efetiva dos trabalhadores no processo. O trabalhador da Instituição é colocado numa situação de passividade, em que sofre as ações programadas e não como um agente das mesmas.

\section{Contribuições da Ergonomia, Ergologia e Clínica da Atividade}

Para registro e mapeamento, a ergonomia aqui tratada é aquela originada em trabalhos de autores franceses, que partem de um entendimento do trabalho nas relações entre o trabalho prescrito e o trabalho real, mas tem como maior especificidade a distinção entre tarefa e atividade, sendo a tarefa como aquilo que pode ser descrito, previsto, necessário ao processo de trabalho, enfim, o que pode ser prescrito e que norteia, e a atividade como espaço de singularidade, de imprevisibilidade, de variabilidade e de encontros. Assim, a ergonomia vai buscar uma compreensão do trabalho no sentido de transformá-lo. 
Como um dos objetivos da ergonomia, a saúde do trabalhador para Falzon (2004, p.231) "deve, portanto, ser entendida como a pesquisa de condições que não somente evitem a degradação da saúde, mas que também favoreçam a sua construção".

Um dos grandes estudiosos da ergonomia francesa, Wisner (1994) enxerga o sujeito/trabalhador como um sujeito social, em situação de trabalho real, que sofre também com a sua condição social. Para esse autor, os problemas de saúde, que podem eventualmente ter origem nos modos de organização do trabalho, estão ligados a alguns erros, que são fatores de inadequação e que resultam, às vezes, num grande lapso entre o que se supõe que o trabalhador faz e o que ele realmente faz.

Os problemas de saúde, ainda na opinião de Wisner (1994, p.19), surgem na relação entre todo o capital do corpo que o sujeito traz (marcas, experiências, modos de vida, etc.) e a situação de trabalho em que ele se coloca ou é colocado. Para esse autor, "podemos considerar que os problemas nascem das relações conflituosas entre a história do individuo e a história da sociedade, sendo tema principal da carga mental de trabalho e do sofrimento psíquico".

Para a abordagem ergológica, o trabalhador em qualquer atividade de trabalho humano é convocado: ele faz uso de si, por si e pelos outros, pois todo trabalho é constituído em dramáticas do uso de si, que se configuram como escolhas e arbitragens, que ocorrem quando se quebra a sequência e o ritmo habitual (DURRIVE e SCHWARTZ, 2008).

Para Brito (2005, p.879), Schwartz observa o trabalho pelo ângulo da vida, ou seja, do trabalho vivo. Afirma a autora que, "encontrar a vida presente no processo de trabalho nos parece fundamental quando pretendemos construir alternativas - em parceria com os protagonistas da atividade - que favoreçam a saúde dos grupos envolvidos".

A saúde é um dos direitos fundamentais que possibilita ao cidadão viver, trabalhar e produzir. A perspectiva da ergonomia, assim como a abordagem ergológica de Schwartz, é inicialmente a busca pela compreensão dos movimentos na atividade relacionados aos movimentos da dinâmica social.

Shwartz e Durrive (2007) descrevem que a atividade é recriação permanente na medida em que promove constante debate de normas. No entanto, esses debates jamais podem ser reconhecidos, avaliados e enquadrados pelos saberes instituídos, de modo instantâneo.

Ao mapear as licenças médicas através de atestados, procurou-se inicialmente identificar as causas desses afastamentos e os dias parados. A reflexão foi além da quantificação e classificação, suscitando a necessidade de outros estudos que possam ampliar o espaço para o diálogo com o trabalhador e para uma construção coletiva de projetos e ações.

\section{Análise dos Dados}

Buscou-se por meio de uma pesquisa documental, verificar as causas e o quantitativo de dias não trabalhados ou "perdidos" por servidores da Universidade Federal do Espírito Santo-UFES.

O mapeamento das licenças médicas identificou que, entre março/2007 e fevereiro/2009, ocorreram 1019 (mil e dezenove) afastamentos por licença médica, totalizando 32133 (trinta e dois mil cento e trinta e três) dias de ausência ao trabalho.

Esse número corresponde a aproximadamente 45 servidores parados para tratamento da própria saúde no período de doze meses e de 90 servidores dentro do período pesquisado ( 2 anos), o que representa pouco 
menos de 3\% do quadro de servidores da Instituição. Esse dado é considerado como uma sub-notificação, visto que muitos servidores se afastam por motivo de saúde sem apresentar atestados e, por isso, não geram dados referentes às licenças, além dos atestados recusados pela Junta Médica Pericial, que não são registrados.

Analisando as causas dos afastamentos registrados, excluídas as causas externas, tem-se que 29,68\% dos afastamentos estão relacionadas a Transtornos Mentais e Comportamentais, seguido por 29,53\% por Doenças do Sistema Osteomuscular e Tecido Conjuntivo, bem como 11,58\% por Neoplasias, e 11,48\% por Doenças do Aparelho Circulatório (Figura 1).

Figura 1

\section{Atestados médicos apresentados no período de março/2007 a fevereiro de 2009}

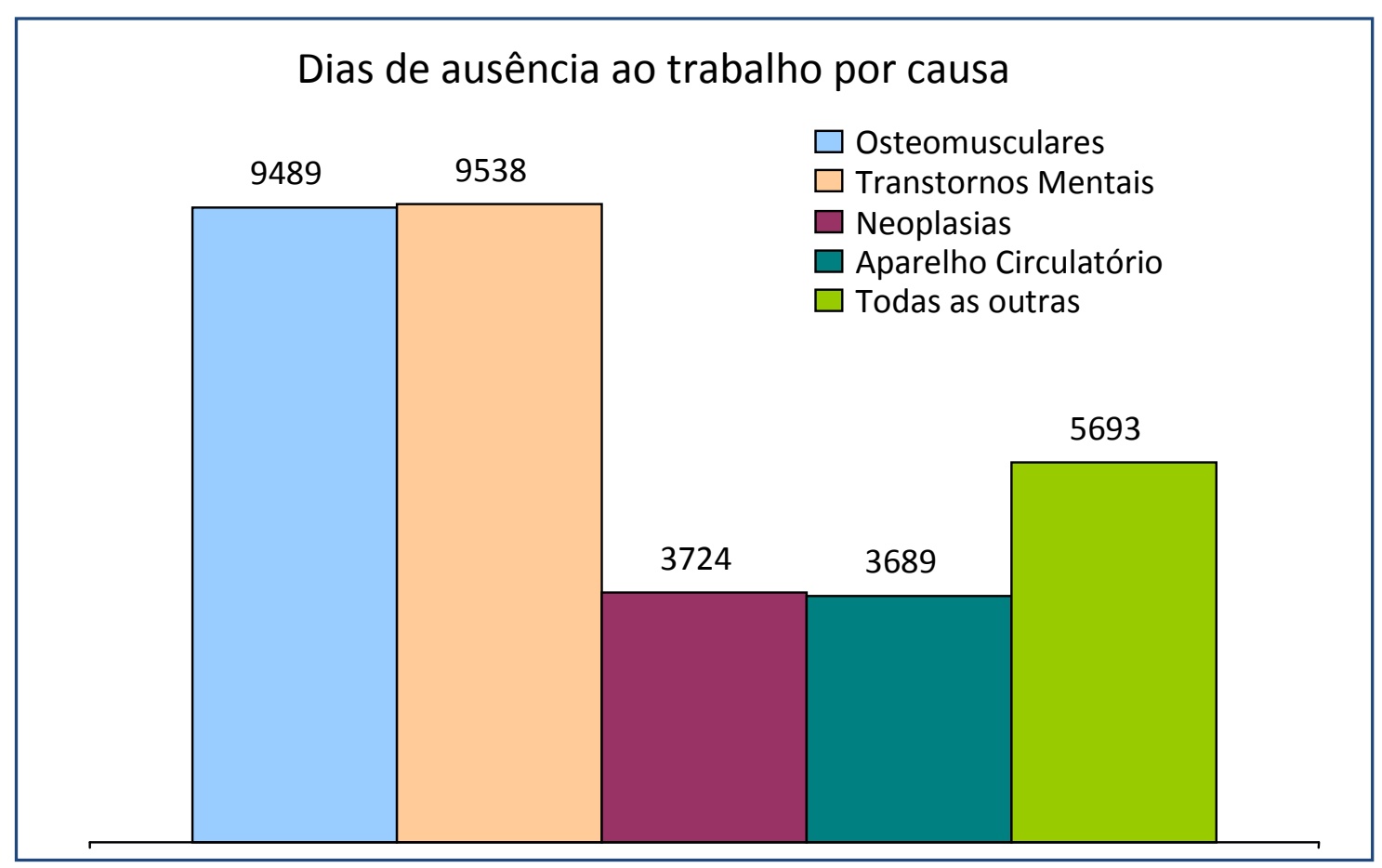

Fonte: Dados da pesquisa (2009).

As principais causas de afastamento permaneceram estáveis nos dois anos pesquisados, sem variação significativa. Destaca-se que as duas principais causas encontradas não apresentam diferença relevante para que se possa determinar uma única causa principal de afastamento, sendo então considerado que as doenças classificadas como Transtornos Mentais e Comportamentais e Doenças do Sistema Osteomuscular e Tecido Conjuntivo representaram, no período analisado, em conjunto, 59,21\% das ausências ao trabalho por licença médica na UFES. 
Quanto ao número de atestados apresentados, o estudo revelou uma discreta diferença. Sendo o número de atestados apresentados com classificação de Transtornos Mentais e Comportamentais superior ao número de atestados apresentados com o código de Doenças do Sistema Osteomuscular e Tecido Conjuntivo.

Apesar da diferença, os dias de ausência ao trabalho se equiparam, representando igual impacto de ausências ao trabalho.

Esse dado pode ser indicativo de que, apesar de ter a mesma representatividade gráfica (Figura 1), os afastamentos por causa de Doenças do Sistema Osteomuscular e Tecido Conjuntivo têm duração maior em número de dias do que aqueles afastamentos gerados pelos Transtornos Mentais e Comportamentais, ou seja, mesmos dias parados com menor número de eventos (Figura 2).

Figura 2

\section{Percentual do quantitativo de licenças por causa}

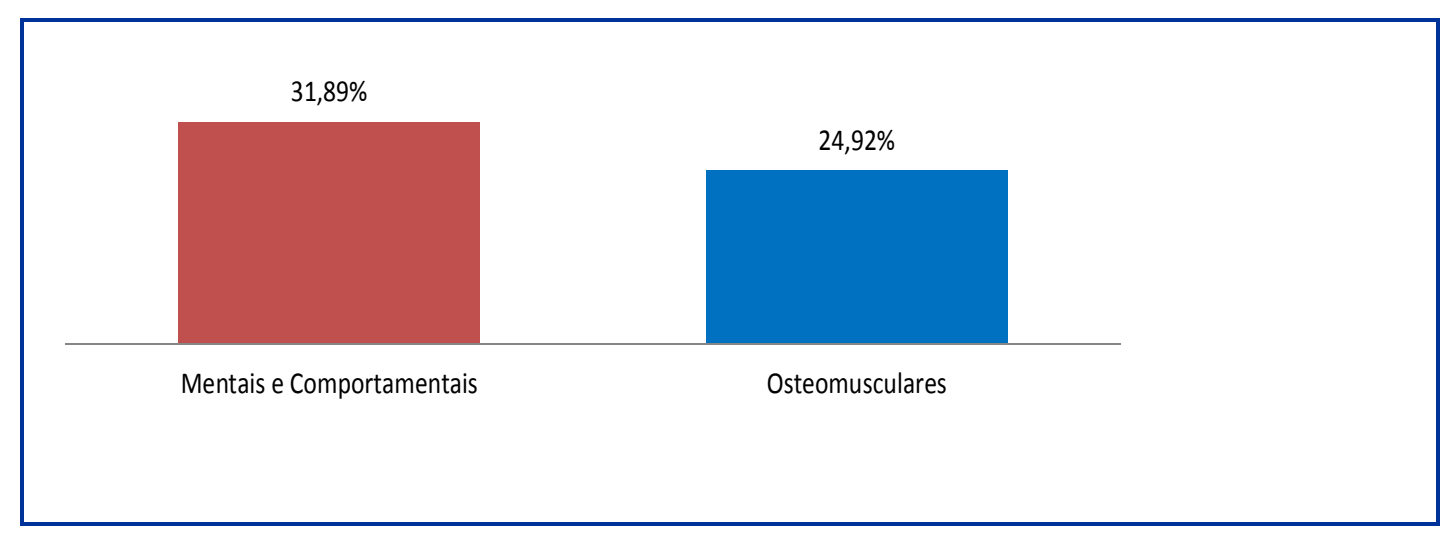

Fonte: Dados da pesquisa (2009).

Com relação ao objetivo desse estudo, foi possível identificar que as duas principais causas de afastamento podem estar relacionadas aos processos de trabalho, o que encontra respaldo em outras pesquisas da área. Borges (2001) apresenta estudo realizado com 155 bancários onde a principal causa de problemas de saúde que necessitaram de consulta médica no período pesquisado foram as Doenças do Sistema Osteomuscular e Tecido Conjuntivo, representando 72,9\%, seguidas dos Transtornos Mentais e Comportamentais, com $33,5 \%$.

A Organização Mundial de Saúde (OMS) estima que os transtornos mentais menores acometam cerca de $30 \%$ dos trabalhadores ocupados, e os transtornos mentais graves, cerca de 5 a $10 \%$. No Brasil, dados do INSS sobre a concessão de benefícios previdenciários de auxílio-doença, por incapacidade para o trabalho superior a 15 dias, e de aposentadoria por invalidez por incapacidade definitiva para o trabalho, mostram que os transtornos mentais ocupam o terceiro lugar entre as causas dessas ocorrências (BRASIL, 2001).

Quanto às Doenças do Sistema Osteomuscular e Tecido Conjuntivo, destacam-se nas últimas décadas as LER/DORT. No Brasil, as estatísticas do INSS revelam que as LER/DORT responderam por mais de $80 \%$ de concessão de benefícios por doenças profissionais, auxílio-acidente e aposentadoria por invalidez em 1998, situação que se repete nos Centros de Referência em Saúde do Trabalhador - CRST, dados revelados 
pelo NUSAT - Núcleo de Referência em Doenças Ocupacionais da Previdência Social. Na universidade pesquisada, não foi verificado se os atestados médicos apresentados referentes ao CID de doenças do Sistema Osteomuscular e Tecido Conjuntivo se relacionavam em maior escala a essa patologia.

Os dados encontrados na UFES apontam para uma relação do processo de adoecimento dos trabalhadores com as relações de trabalho. Não se pretende aqui configurar uma relação de causa-efeito, mas indicar uma necessidade premente de refletir e discutir qual o trabalho e saúde que se tem e qual o trabalho e saúde que se quer; o trabalho e a saúde dentro da vida que se constrói todo tempo como experiência única, singular de um coletivo.

A análise dos dados permite apenas uma leitura superficial da realidade desses trabalhadores, mas possibilita um primeiro olhar sobre o processo de saúde do trabalho nessa Universidade, sendo um ponto de partida para outros estudos e para entender, conforme propõe Martins (2004, p.30), como as construções do trabalhador com o seu trabalho e com sua saúde são fundamentais para viabilizar uma tensão entre nossas "forças e fraquezas, presente e singular, que vivenciamos quando e sempre que conseguimos potencializar nossa vida em momentos difíceis".

Essas considerações reforçam o pensamento de que é possível diminuir o absenteísmo e melhorar a qualidade de vida dos trabalhadores, ao ampliar os espaços de discussão, valorizar a autonomia dos sujeitos na organização da atividade trabalho, tendo como referencial o próprio trabalhador e a reflexão sobre suas práticas.

As intervenções possíveis numa análise do trabalho podem ser muito mais efetivas, se a proposta convocar o trabalhador para esse debate, ampliando as pesquisas para além do olhar da academia.

O esforço é numa interação dos especialistas com os trabalhadores, visão referendada pela análise ergonômica da atividade, proposta pela ergonomia, bem como pela Comunidade Ampliada de Pesquisa, como traz Clot (2007b), e particularmente na metodologia de articulação dos saberes, nos três polos proposta por Schwartz (2000, p.45): o primeiro polo, com os saberes produzidos pelos especialistas na academia; o segundo polo, pelos saberes gerados pelos próprios trabalhadores na sua atividade; e o terceiro polo, que permite a relação dialógica dos outros dois, sendo que esse último, segundo o autor, "impõe, de uma parte, uma certa humildade dos universitários para retomar a palavra à atividade e, de outra parte, uma aceitação da disciplina do conceito e de sua aprendizagem pelos protagonistas das atividades".

Coimbra (2003) discute a questão dos especialismos, onde saberes fragmentados recortam o sujeito de sua produção sócio-histórica, construindo práticas baseadas na hierarquia, individualização e desqualificação deste. Segundo a autora, é necessária a renúncia aos modelos, às identidades, às permanências, às homogeneidades construindo uma prática transdiciplinar que permita a reinvenção do fazer.

Tendo como certa a inevitável interação do homem com o trabalho, essas considerações possibilitam também uma reflexão sobre o trabalho dos profissionais de saúde na instituição pesquisada, alertando para a necessidade de ouvir o trabalhador, ou mais que isso, propiciar que o trabalhador retome a palavra, incitando uma discussão que não somente evite a degradação da saúde, mas que, numa abordagem ativa da saúde do trabalhador, amplie as possibilidades de construção e reinvenção da relação saúde e trabalho.

\section{Considerações Finais}

A pesquisa é sempre possibilidade de sair de uma situação de mero reconhecimento/desconhecimento dos rituais práticos da vida cotidiana, para produzir conhecimento dos dispositivos engendrados na atividade, desnaturalizando formas cotidianas de existência. Tal afirmação valida a experiência e o saber dos 
trabalhadores, assim como mobiliza os próprios participantes/pesquisadores, o que possibilita a transformação das condições e dos processos de trabalho (ALTHUSSER, 1980).

Nesse sentido, a proposta deste estudo é constituir-se como um disparador para a criação de possíveis espaços de troca, de construção, análise e problematização das práticas em saúde do trabalhador no cotidiano universitário.

Os ganhos desta reflexão são plurais, não apenas no sentido de todos os envolvidos no processo, mas nas possibilidades que se abrem para avançar no tema. Muito ainda pode ser feito, por exemplo, um estudo que identifique outras variáveis, como questão de gênero, tempo de trabalho, tipo de atividade exercida, relacionados ou não à prevalência de doenças identificadas, além de outros estudos qualitativos para interagir com o trabalhador e melhor entender como ele percebe a interface saúde e trabalho, trazendo-o para discutir os processos de trabalho e sua saúde.

Os dados da pesquisa são frágeis para permitir uma análise ampla do processo de construção da saúde do trabalhador, mas robustos para permitir um olhar sobre a saúde, o adoecimento, o absenteísmo, ou qualquer questão inerente ao trabalho de forma integrada à vida.

Pensando o trabalho como lugar de produção de saúde, e por isso mesmo lugar de adoecimento, entende-se que os transtornos mentais e comportamentais e as doenças do sistema osteomuscular e tecido conjuntivo que predominam na população pesquisada são apenas a emergência de outros processos que os subsidiam. Resultam, portanto, não de fatores isolados, mas de contextos de trabalho em interação com o corpo e aparato psíquico dos trabalhadores.

Muitos que desconhecem o processo de construção da saúde e adoecimento tendem a se culpar pelo aparecimento de suas doenças, não as relacionando com o trabalho e com sua vida de modo geral. Ao não entender como o processo de trabalho pode interferir nesse processo, o trabalhador fica impossibilitado de adotar posturas conscientes, bem como cobrar melhores condições e informações, posicionando-se como autor/ator nessa construção.

A autonomia do indivíduo consiste na liberdade para refletir sobre si, como fonte de criação e alteração, capaz de alterar o sentido para ele mesmo e ter um papel ativo num ser autônomo. Dessa maneira, para que indivíduos possam ter oportunidade para esses questionamentos, as organizações também devem ter brechas para essa liberdade, com um maior espaço de ação, reflexão e construção.

O texto de Jardim (2001, p.141) é muito pertinente para concluir este trabalho, ao provocar as instituições e profissionais de saúde dizendo que "está na hora de invertermos a questão e, ao invés de invalidarmos pessoas, começarmos a invalidar condições, processos e a organização do trabalho que invalidam pessoas". Este estudo alcança os seus objetivos ao dar um primeiro passo, e a partir dele propiciar uma reflexão sobre as práticas atuais e as possibilidades que se abrem. 


\section{Referências}

ALTHUSSER, L. Posições II. Rio de Janeiro: Graal, 1980.BORGES, L. H. As lesões por esforços repetitivos (L.E.R.) como índice do mal-estar no mundo do trabalho. In: BORGES, L. H.; MOULIN, M.G.B.; ARAÚJO, M.D. (Orgs.). Organização do Trabalho e Saúde: múltiplas relações. Vitória: EDUFES, 2001. p. 157-174.

BRASIL. Ministério da Saúde. Doenças relacionadas ao trabalho: manual de procedimentos para os serviços de saúde. Brasília, 2001. (Normas e Manuais Técnicos, n.114).

BRITO, J. Saúde do trabalhador: reflexões a partir da abordagem ergológica. In: FIGUEIREDO, M.; ATHAYDE, M.; BRITO, J.; ALVAREZ, D. (Orgs.). Labirintos do trabalho: interrogações e olhares sobre o trabalho vivo. Rio de Janeiro: DP\&A, 2004. p. 91-114.

. Trabalho e saúde coletiva: o ponto de vista da atividade e das relações de gênero. Ciênc. saúde coletiva, v.10, n.4, p. 879-890, 2005.

CANGUILHEM, G. O normal e o patológico. Rio de Janeiro: Forense Universitária, 1990.

CLOT, Y. A função psicológica do trabalho. Petrópolis: Vozes, 2007a.

História da Psicologia do Trabalho na França. (Conferência). Transcrição e revisão de Neide Ruffeil e Claudia da Silva Osório. Rio de Janeiro: UFF, 2007b, p. 3-63.

COIMBRA, C.; LEITAO, M. B. S. Das essências às multiplicidades: especialismo psi e produções de subjetividades. Psicologia e Sociedade, v.15, p. 6-17, 2003.

COUTO, H. A. Contribuições da ergonomia, higiene, segurança e medicina do trabalho para a qualidade de vida. 2005. Disponível em: htttp://www.ergoltda.com.br/ergonomia. Acesso em: 23 set. 2009.

DANIELLOU, F. Introdução: questões epistemológicas acerca da ergonomia. In: DANIELLOU, F. et al. (Orgs.) A ergonomia em busca de seus princípios: debates epistemológicos. São Paulo: Edgard Blucher, 2004. p.1-29.

DEJOURS, C. Por um novo conceito de saúde. Revista Brasileira da Saúde Ocupacional, v.14, n.54, p. 27-35, abr./jun. 1986.

A loucura do trabalho: estudo da psicopatologia do trabalho. São Paulo: Cortez, 1992.

DURRIVE, L.; SCHWARTZ, Y. Glossário da Ergologia. Laboreal, v.4, n.1, p. 23-28, 2008. Disponível em: http://laboreal.up.pt/revista/artigo.php?id=48u56oTV6582234396587. Acesso em: 17 fev. 2010.

FALZON, P. Os objetivos da ergonomia. In: DANIELlOU, F. et al. (Orgs.). A ergonomia em busca de seus princípios: debates epistemológicos. São Paulo: Edgard Blucher, 2004. p. 214-237.

GOMES-MINAYO, C.; THEDIM-COSTA, S. A construção do campo da saúde do trabalhador: percurso e dilemas. Cad Saúde Pública, Rio de Janeiro, v. 13, p. 21-32, 1997. Suppl. 2.

JARDIM, S.R. Trabalho e Doença Mental. In: BORGES, L.H.; MOULIN, M.G.B.; ARAÚJO, M.D. (Orgs.): Organização do Trabalho e Saúde: múltiplas relações. Vitória: EDUFES, p.137-156, 2001.

MAGGI B.; TERSAC. G. O trabalho e a abordagem ergonômica. In: DANIELLOU, F. et al. (Orgs.). A ergonomia em busca de seus princípios: debates epistemológicos. São Paulo: Edgard Blucher, 2004. p. 97-119.

MARTINS, A. Biopolítica: o poder médico e a autonomia do paciente em uma nova concepção de saúde. Interface Comunic., Saúde, Educ. v. 8, p. 21-32, 2004. 
MENDES, R.; DIAS, E. C. Da medicina do trabalho à saúde do trabalhador. Revista de Saúde Pública, v.25, p. 341349, 1991.

PENATTI, I.; ZAGO, J.S.; QUELHAS, O. Absenteísmo: as consequências na gestão de pessoas. 2006. Disponível em: <www.aedb.br/seget/artigos06/898_Seget_Izidro\%20 Penatti.pdf>. Acesso em: 30 maio 2010.

SATO, L. Saúde, meio ambiente e condições de trabalho. In: BORGES, L. H.; MOULIN, M. G. B.; ARAÚJO, M. D.(Orgs.). Organização do trabalho e saúde: múltiplas relações. Vitória: Edufes, 2001. p. 71-86.

Prevenção de agravos à saúde do trabalhador: replanejando o trabalho através das negociações cotidianas. Cad. Saúde Pública. n.18, p.1147-1157, 2002.

SCHWARTZ, Y. Trabalho e uso de si. Proposições, n.1, p. 25-39, 2000.

SCHWARTZ, Y.; DURRIVE, L. Trabalho e Ergologia: conversas sobre a atividade humana. Niterói: EdUFF, 2007.

SILVA, L. S.; PINHEIRO, T. M.; SAKURAI, E. Perfil do absenteísmo em banco estatal em Minas Gerais: análise no período de 1998 a 2003. Ciência e Saúde Coletiva, n.13, p.2049-2058, 2008.

WISNER, A. A inteligência no trabalho: textos selecionados de ergonomia. São Paulo: Fundamento, 1994. 